\title{
EDITORIAL
}

\section{New advances in unconventional resources: accumulation and production-introduction to the special issue}

\author{
Yong LI (ه) ${ }^{1}$, Junqian LI $^{2}$, Derek ELSWORTH ${ }^{3}$ \\ 1 College of Geosciences and Surveying Engineering, China University of Mining and Technology, Beijing 100083, China \\ 2 School of Geosciences, China University of Petroleum (East China), Qingdao 266580, China \\ 3 Department of Energy and Mineral Engineering, Geosciences, EMS Energy Institute and the G3 Center, Pennsylvania State University, University \\ Park, PA 16802, USA
}

(C) Higher Education Press 2021

\section{Introduction}

The recovery and utilization of unconventional resources over the last decade-and-a-half, especially shale oil and gas, has developed and continues to play a decisive role in worldwide energy supply and markets (Bustin, 2012; Zou et al., 2010 and 2019). Ongoing and expanding production from unconventional resources counters burgeoning demand and has exerted an increasing impact on petroleum prices and global energy structure. This, albeit short, history of unconventional oil and gas production provides a rich set of 'lessons learned', with further progress expected to catalyze the development of new technologies. However, as fossil fuels, unconventional hydrocarbons also face pressure from the expansion and diversification of renewable and alternative energy resources. An urgent need is to demonstrate that unconventional resources can be recovered at scale and that recovery is both economically-viable and environmentally-friendly (Cui et al., 2019; Gao et al., 2021).

This special issue showcases new advances related to the evaluation and recovery of unconventional energy resources, illustrating fundamental theories, applied technologies and field practices. A collection of 19 papers is compiled in this issue, mainly focusing on new advances in coalbed methane, shale gas, shale oil, tight gas and tight oil and related to geological evaluation and performance in production-principally in China.

A total of six papers relate to coalbed methane with the first three comprising reviews for first coalbed reservoir petrophysical characteristics (two) and then the hysteresis of methane desorption. Of the remaining three of these six, one reports on reservoir characterization methods combining SAXS and nano-CT, one discusses biogenic methane generation, and two reporting coalbed methane (CBM) reservoirs and accumulation model of the low rank coal in the southern Junggar Basin.

A further nine research papers relate to the accumulation and recovery of shale gas. Two of the nine detail the adsorption characteristics of shale gas and the quantitative evaluation of adsorbed gas content, and one of them discuss the competitive adsorption behavior of $\mathrm{CH}_{4}$ and $\mathrm{CO}_{2}$. A further three of the nine focus on shale gas enrichment and factors exerting geological control, analyze differential enrichment processes and then explore influences of structural evolution, reservoir conditions, material composition and microstructure on shale gas accumulation. One paper reports an evaluation method for organic richness combining well logs and geochemical data. One paper explores the microstructure of marine, transitional, and continental shales pores and analyze the influence of diagenesis. One paper then explores the quantitative characterization of the production characteristics of shale gas horizontal wells and another demonstrates the environmental risks of shale gas recovery and their potential mitigation.

Two articles then address shale oil enrichment, first related to the control of rock fabric facies on shale oil enrichment and then on the relationship of shale oil phase state with shale oil composition.

Received September 24, 2021

E-mail: liyong@cumtb.edu.cn 
Finally, two papers address tight oil and gas, detailing the distribution and characteristics of tight sandstone gas reservoirs and in defining physical-property cutoffs for tight oil reservoirs in sandstone.

\section{Overview of special issue papers}

This grouping of papers addresses the topical areas of hydrocarbon accumulation and production for methane in coalbeds, shales and tight sandstone reservoirs and for shale oil.

2.1 Coalbed methane accumulation and production advances

As two methods effectively used in coal and shale reservoirs, small-angle X-ray scattering (SAXS) and nano-CT methods were combined to characterize the nano- to micropore structure of two bituminous coal samples by Prof. Zhao et al. (2021, this issue P189-P201) The fractal dimensions estimated by both methods for different pore sizes show consistency with the sample returning smaller average pore diameters having a more complex pore structure within the full tested range.

Jia et al. (2021, this issue P202-P223) present a review of petrophysical characteristics of CBM reservoirs, primarily focusing on the characterization of pore-fractures by nuclear magnetic resonance (NMR) imaging, by porosimetry using liquid nitrogen and mercury intrusion, through high-precision imaging (focused-ion beamscanning electron microscopy, small-angle neutron scattering, X-ray computed tomography and m-CT scanning) and through X-ray diffraction. They also discuss the important role of tectonic stress in controlling coal permeability, as well as the lithologic heterogeneity of deep coals.

A review of methane desorption hysteresis in coal reservoirs is reported by Xu et al. (2021, this issue P224-P236). This review highlights the mechanisms of desorption hysteresis and its controlling factors as well as methods and models to define and characterize this hysteresis. CBM desorption processes are explored for different rank coals subjected to different temperatures, pressures, and water saturations conditions. Approaches invoking molecular thermodynamics and surface physical chemistry are defined to provide a quantitative understanding of desorption mechanisms.

To define the potential for CBM production in the Junggar Basin, a full-scale characterization of the high volatility bituminous coal was conducted and reported by Zhao et al. (2021, this issue P237-P255) The pore size distribution was determined by combining the corrected mercury intrusion porosimetry data with low-temperature nitrogen adsorption data. The relationship between transverse relaxation time $\left(T_{2}, \mathrm{~ms}\right)$ and mean pore diameters was determined by comparing the $T_{2}$ spectrum with the pore size distribution recovered from the porosimetry. Macro-pore and pore-throat size distributions derived from nano-CT and rate-controlled mercury penetration were correspondingly constrained and reported.

Hou et al. (2021, this issue P256-P271) present CBM enrichment models of low rank coals in the multi-coal superimposed regions of the southern Junggar Basin. The controlling effect of sedimentary, tectonic and hydrogeological environments on gas content was analyzed in detail. Their model identifies both biogenic and thermogenic origins for the methane found at burial depths in the interval $600 \mathrm{~m}$ to $850 \mathrm{~m}$, suggesting that those coals are the most generously enriched and thus comprise the most favorable exploration regions in the middle section of the southern Junggar Basin.

Wang et al. (2021, this issue P272-P282) complete a simulated experiment on biogenic gas generation and study the effects of gas generation on the pore structure and molecular structure of anthracite using mercury intrusion porosimetry, X-ray diffraction (XRD) and Fourier transform infrared spectroscopy (FT-IR). The results show that methanogenic bacteria can produce biogenic gas from anthracite. $\mathrm{CO}_{2}$ and $\mathrm{CH}_{4}$ are the main components of the generated biogas.

\subsection{Shale gas accumulation and production advances}

Wang et al. (2021, this issue P283-P300) perform an experimental study on the adsorption behavior of $\mathrm{CH}_{4}$ and $\mathrm{CO}_{2}$ on marine and continental shales at different temperatures, and investigates the influences of mineral composition and pore structure on the adsorption behavior. Both $\mathrm{CH}_{4}$ and $\mathrm{CO}_{2}$ adsorption capacity in the shales have positive correlations with total organic carbon (TOC) and clay mineral content due to the development of larger micropores, corresponding increased mesopore volume and specific surface area. $\mathrm{CO}_{2}$ adsorption capacity of the shales is greater than for $\mathrm{CH}_{4}$ which indicates the feasibility for $\mathrm{CO}_{2}$ enhanced shale gas recovery. Both TOC and brittle mineral contents together with temperature impact the selective adsorption coefficient of $\mathrm{CO}_{2}$ over $\mathrm{CH}_{4}$. 
Nie et al. (2021, this issue P301-P309) provide a new method of evaluating the in-place adsorbed gas content of organic-rich shales from in situ wireline logging data. They studied the relationships among temperature, TOC, organic matter maturity and adsorbed gas content and defined qualitative relations among these parameters. These relations, when combined, enabled adsorbed gas content to be defined based on depth and TOC. This model is then available to estimate adsorbed gas content using conventional well logging data, alone.

The lower Cambrian Niutitang Formation is of crucial importance as a shale gas target reservoir in China. Xu et al. (2021, this issue P310-P331) investigate the geological controls on shale gas accumulation in the Lower Cambrian Niutitang Formation in the Middle Yangtze in China and explore the enrichment mechanism of the shale gas. The vertical distribution of gas content is mainly affected by the TOC content. Laterally, a combination of structural styles, fault and fracture development and the distribution of the regional unconformity boundary between the Upper Sinian Dengying Formation and the Niutitang Formation are the three most important controls on gas content.

Pyrite is a key component in many shales and plays a crucial role in shale gas enrichment. Chen et al. (2021, this issue P332-P342) investigate the impact of pyrite on shale gas enrichment in the Lower Silurian Longmaxi Formation of the southeast Sichuan Basin, China, by using outcrops, drilling cores, thin sections, and test data. Result shows that the formation and content of pyrite has a close correlation with TOC content. Pyrite can promote shale gas enrichment by absorbing shale gas on its surface and preserving free gas in the interparticle pores and organic matter pores.

Chen et al. (2021, this issue P343-P359) explore the differences in dynamic shale gas accumulation processes related to the burial history of shale gas reservoirs and discuss its significance in the exploration of the Lower Silurian Longmaxi Formation in northeast Yunnan, China. The results show that differences in the burial history of marine shales in the Longmaxi Formation can be related to synclinal and anticlinal forms with the shale gas accumulation process divided into four stages. Based on the characteristics of the burial history and preservation conditions, priority structural locations for shale gas exploration may be determines, and are applied in reservoirs in northeast Yunnan.

Transitional shale gas is a potential natural gas exploration hotspot, with extensive work, mainly focusing on Permian both in north and south China, being conducted recently (Li et al., 2019). Tang et al. (2021, this issue P360P377) report the identification of organic matter richness in transitional shales and the mechanism of organic matter enrichment. Well logging data including natural gamma-ray (GR), density (DEN), acoustic (AC), neutron (CNL) and $\mathrm{U}$ spectral gamma-ray $(\mathrm{U})$, and TH spectral gamma-ray $(\mathrm{TH})$ were applied in this study. And the multivariate fitting method of GR-UDEN-CNL combination is preferable, with high correlation coefficients both for entire and objective interval of the Taiyuan Formation.

Xie et al. (2021, this issue P378-P394) investigate the controls of sedimentation and diagenesis on pore structure in typical marine, transitional, and continental shales. For pore structure, both micropores $(0-2 \mathrm{~nm})$ and mesopores $(2-50 \mathrm{~nm})$ control overall pore volume and specific surface area of transitional and marine shales. The specific surface area of continental shales behave similarly, while micropores, mesopores, and macropores (>50 nm) all comprise a significant proportion of pore volume in continental shales. Apparently, pore structure characteristics and controlling factors exhibit a pronounced difference in different stages of diagenesis.

Yu et al. (2021, this issue P395-P405) completed quantitative characterization of horizontal well production performance using multiple indicators- based on a case study of the Weiyuan shale gas field in the Sichuan Basin, China. A practical productivity method incorporating multiple indicators (including normalized test production, flowback ratio, first-year initial production and estimated/expected ultimate recovery (EUR)) was proposed to analyze the production performance of 150 horizontal wells. Well productivity was shown to be greatly dependent on the lateral target interval, drilling length and wellbore integrity.

Gao et al. (2021, this issue P406-P422) present a comprehensive investigation on the environmental risks of shale gas recovery by using systematic analyses and detailed field data, to provide a suggested solution for clean shale gas production in China. Environmental challenges mainly include seasonal water shortages, requisition of primary farmland, leakage of drilling fluid and infiltration of flowback fluid, disposal of oil-based drill cuttings underground and the potential for induced seismicity. A proposed clean production model for shale gas focuses on source pollution prevention, process control and tertiary treatment, which yield significant results in terms of resource as well as environmental protection.

\subsection{Shale oil accumulation and production advances}

Compared to marine shale oil in North America, efficient exploration of lacustrine shale oil in China is more difficult due to more complex reservoir conditions. Han et al. (2021, this issue P423-P437) analyze then classify favorable rock fabric facies for oil accumulation based on systematic coring of approximately $500 \mathrm{~m}$ fine-grained deposits of 
the Kong 2 Member. Their analysis combines laboratory tests and log data, source rock geochemistry and reservoir physical properties. A total of 10 fabric facies were classified, with 4 fabric facies found to have high TOC content, high total hydrocarbon and strong fluorescence features, indicating favorable shale oil enrichment.

Bai et al. (2021, this issue P438-P456) evaluate the properties of shale oils in different phase states and investigate how these differences are related to initial shale composition. As a case study, shale oil from the Qingshankou (Q1) Formation from the Songliao Basin of China was analyzed. Fluorescence techniques were used to quantitatively determine the content and properties of the free oil (FO), the adsorbed oil associated with carbonate (ACO), and the adsorbed oil associated with silicate and clay-organic complexes (AKO). Result show that nonhydrocarbons and asphaltenes are the primary fluorescing compounds present on the shale grain surfaces. FO is the dominant phase in the Q1 Formation. ACO and AKO hydrocarbons are heavier than FO hydrocarbons and FO has a high content of relatively light hydrocarbons and the strongest fluidity.

2.4 Tight gas and tight oil accumulation and production advances

Luo et al. (2021, this issue P457-P470) evaluate the distribution and characteristics of tight gas reservoirs in the $\mathrm{H}_{8}$ Member of the Shihezi Formation of the Sulige gas field in the Ordos Basin of northwest China. They divide the effective reservoir into three types (I, II and III), which differ greatly in size, porosity, permeability, and saturation. Compared with conventional gas reservoirs, effective tight gas reservoirs are small-scale and have low gas saturation. Results show that the scale of the sedimentary system controls the size of the dominant microfacies in which tight gas effective reservoirs form.

A comprehensive investigation of cutoffs in physical properties in tight sandstone reservoirs is of significance for the accurate evaluation of reservoirs and their successful exploration. Shi et al. (2021, this issue P471-P489) use the tight sandstone reservoir formations from Chang 6,8 and 9 units in the Ordos Basin as an example and determine the physical-property cutoffs by using field and laboratory experiments. The results show that the porosity cutoffs of the Chang 6, Chang 8 , and Chang 9 oil layers are $7.9 \%, 6.4 \%$, and $8.6 \%$, and the corresponding permeabilities are $0.08 \mathrm{mD}, 0.05 \mathrm{mD}$, and $0.09 \mathrm{mD}$, respectively. The cut-offs of the thickness of single-layer effective reservoirs are approximately $3.0 \mathrm{~m}, 3.0 \mathrm{~m}$, and $2.0 \mathrm{~m}$, respectively.

Acknowledgements We thank the representative colleges of the China University of Mining and Technology (Beijing), China University of Petroleum (East China), and Pennsylvania State University for supporting the compilation of this special issue. Dr. Beibei Liu of the Higher Education Press and Dr. Xiaoyu Chen of the East China Normal University helped coordinate this special issue.

\section{References}

Bustin R M (2012). Shale gas and shale oil petrology and petrophysics. Int J Coal Geol, 103: 1-2

Cui J, Zhu R, Mao Z, Li S X (2019). Accumulation of unconventional petroleum resources and their coexistence characteristics in Chang 7 shale formations of Ordos Basin in central China. Front Earth Sci, 13(3): 575-587

Gao S K, Guan Q Z, Dong D Z, Huang F (2021). Environmental risks of shale gas exploitation and solutions for clean shale gas production in China. Front Earth Sci

Li Y, Wang Z, Gan Q, Niu X, Xu W (2019). Paleoenvironmental conditions and organic matter accumulation in Upper Paleozoic organic-rich rocks in the east margin of the Ordos Basin, China, Fuel, 252: 172-187

Zou C, Dong D, Wang S, Li J, Li X, Wang Y, Li D, Cheng K (2010). Geological characteristics, formation mechanism and resource potential of shale gas in China. Pet Explor Dev, 37(6): 641-653

Zou C, Yang Z, Zhang G (2019). Establishment and practice of unconventional oil and gas geology. Acta Geol Sin, 93: 12-23 